\title{
Ensino-aprendizagem à Distância e Revolução na Informação: Implicações Psicológicas e Pedagógicas das Novas Realidades ${ }^{1}$
}

\author{
Samuel Pfromm Netto ${ }^{2}$ \\ PUC-Campinas/USP /CIANET, SP.
}

\begin{abstract}
Resumo
Desenvolvimentos recentes em educação à distância, tecnologia educacional e mídia educativa estão alterando concepções, práticas e recursos na aprendizagem e no ensino, e estão igualmente a exibir a atenção e o envolvimento dos psicólogos escolares e educacionais no mundo inteiro. São aqui considerados vários pontos essenciais relativos à crescente utilização de recursos tecnológicos como o vídeo, a Internet, o áudio, os CDRom e outros, no campo da educação, no contexto da nova sociedade global e de informações em que começamos a viver.
\end{abstract}

Palavras chaves: Tecnologia de ensino, tecnologia educacional, revolução na educação.

\section{Distance Teaching-learning and Revolution in Formation: psychological and pedagogical implications of new realities}

\section{Summary}

Recent developments in distance education and educational technology and media are changing conceptions, posictices and resources in learning and teaching and also demanding the attention and involvement of school psychologists and Educational Psychologists everywhere. Here are considered several keypoints related to the expanding utilization of technological resources like video, Internet, audio, CD-Rom and others in the educational field - in the context of the new global and information society in which we begin to live.

Key words: Teaching technology, educational technology, revolution in education.

Foi em 1926. Há 72 anos, Edgard Roquette-Pinto iniciou no Brasil a educação à distância pelo rádio, valendo-se da Rádio Sociedade PRA-2, que ele e Henrique Morize criaram na então Capital Federal três anos antes. Esse brasileiro genial, misto de professor, cientista, homem de letras e empreendedor lançou também as bases do cinema educativo no país e foi pioneiro em pesquisas sobre televisão. Por ocasião do nascimento do rádio a serviço da educação no país, Roquette-Pinto falou entusiasmado sobre as perspectivas que se abriam, graças ao rádio, ao cinema e à futura televisão (que naqueles tempos se achava ainda em fase experimental) como grandes escolas do povo, como meios gigantes para se democratizar o acesso ao conhecimento, às artes, às técnicas, à cultura.

Mais ou menos à mesma época, psicólogos e pedagogos, tanto aqui como no exterior, iniciavam as pesquisas sobre o ensino-aprendizagem por meio dos chamados "recursos audiovisuais" que, além do cinema e do rádio, incluíam principalmente cartazes, estampas e mapas, materiais e equipamentos de projeção fixa e gravações de som em discos de 78 rotações.

Dá gosto percorrer as páginas das histórias da educação e da psicologia nas primeiras décadas do século atual e encontrar nelas, como pioneiros da pesquisa e do incentivo ao uso do

\footnotetext{
${ }^{1}$ Conferência proferida no IV Congresso Brasileiro de Psicologia Escolar, em João Pessoa, PB, 1998.

${ }^{2}$ Endereço: Rua Itambé, 186. apto. 55 Higienópolis CEP: 01239-000 São Paulo-SP - Brasil.
} 
cinema ou do rádio educativos, um John Broadus Watson, o pai do behaviorismo, nos Estados Unidos, e um Lourenço Filho, um Venâncio Filho ou Jonatas Serrano, no Brasil. A verdade é que há muito tempo se descobriu que ensinar e aprender podem ser sensivelmente favorecidos e beneficiar incomparavelmente mais estudantes do que os que cabem numa sala de aula, quando mobilizamos esses recursos portentosos que possibilitam o registro permanente de mensagens de ensino, a sua propagação em escala até mesmo planetária, ou ambas as coisas, como ocorre com o filme cinematográfico, a gravação em fita de vídeo ou o CD- Rom.

Poderá, talvez, parecer estranho que, num congresso devotado à Psicologia Escolar, as temáticas da Educação à Distância e da Tecnologia Educacional mereçam as honras de toda uma conferência. Afora a boa-vontade dos organizadores do congresso, que acolheram nossa sugestão nesse sentido, e a boa-vontade dos que se dispõem a ouvir este expositor, há uma razão maior que está por trás desta contribuição. É o imperativo praticamente universal e urgente de reconsiderar o ensino e a aprendizagem, fora dos quadros convencionais que herdamos de um passado muito distante, que os reduziam aos termos professor, aluno, carteira, quadro negro, giz e cadeiras, ou pouco mais que isso.

Já nos anos sessentas e setentas, diversas vozes das mais respeitáveis nos mundo da psicologia a serviço da educação e da pedagogia nos alertaram para necessidade de um repensar, um refazer, um inovar em matéria de educação. Em meados da década de 60, nos Estados Unidos, eu tive a ventura de aprender com Carl Rogers como se pode ensinar psicoterapia com muito mais eficiência por meio do cinema ou do vídeo; com Skinner, como os princípios do condicionamento operante podem ser traduzidos em práticas docentes e em materiais didáticos como os textos programados e as "máquinas de ensinar", precursores do uso do computador no ensino; com Gagné, como as bases científicas de aprendizagem humana nos ajudam a melhorar sensivelmente o ensino que proporcionamos a pessoas de todas as idades, da pré-escola aos programas destinados a idosos, nos contextos de educação formal e informal e do treinamento.

Em 1972, nesta obra verdadeiramente preciosa que é Apprendre à être, de Faure e colaboradores, e em um dos seus mais belos capítulos, denominado "Faits porteurs d'avenir" - Fatos portadores do futuro, o saudoso Henri Dieuzeide, autoridade mundialmente reconhecida em matéria de comunicação educativa, afirmava que "o futuro da educação reside nas instituições educativas que combinam a eficácia dos organismos com base industrial ou tecnológica centrados na aquisição do saber com a vitalidade dos grupos criadores, cuja ação possibilita a evolução das relações, humanas". Conforme assinala Federico Mayor no prefácio da obra póstuma de Dieuzeide, Les Nouvelles Technologies, editada em 1994, o grande sonho de Dieuzeide sempre foi o de "aliar, na educação e pela educação, as forças de participação democrática e o poder da imaginação às possibilidades abertas pela tecnologia da comunicação e da informação, de maneira a liberar o potencial criador das pessoas e os recursos latentes das coletividades". Além disso, Dieuzeide via no emprego racional dos meios técnicos e científicos um recurso poderoso para os países menos desenvolvidos na direção da educação para todos; "ele saudou a Comissão Internacional para a Educação no Século 21, encarregada de reexaminar sob nova luz as estruturas, os conteúdos e os métodos da educação e de propor soluções para os problemas que aguardam solução às vésperas do ano 2000". Nos seus escritos, nas suas pesquisas, nas suas ações, Dieuzeide foi um batalhador incansável em favor do ensino à distância, da educação aberta e das novas tecnologias educacionais. Um batalhador que, muito ao contrário de certos gênios pedagógicos de botequim, acreditava nas 
tecnologias educacionais e no ensino à distância como grandes forças geradoras de mais democracia e mais liberdade na sociedade. "A educação, hoje em dia," diz ele nos derradeiros parágrafos do livro citado, "está mais livre do que nunca para modular, manipular e resolver as tecnologias, para lhes dar finalidades originais e microobjetivos apropriados"; podemos, graças a essas novas tecnologias a serviço do ensino, "otimizar a ação docente e maximizar a auto-aprendizagem de cada estudante, base da sua formação profissional, cívica e cultural" (p.229).

Às vésperas do início do novo milênio, cabe a nós, psicólogos, a nós, educadores no Brasil, uma tarefa árdua, imensa e extremamente desafiadora que, longe de ser um desses exercícios intelectuais mais ou menos inócuos que tanto agradam aos mais pensantes, tem conseqüências e implicações extremamente sérias para o futuro próximo e distante do Brasil como povo e como nação. A partir dos alicerces levantados ao longo desta segunda metade do século e com plena consciência das profundas e generalizadas mudanças em curso no mundo, sob todos os aspectos, com os realinhamentos em escala global, os portentos da era da informação e de informática e tantas outras "novas realidades" atordoantes, nosso Titanic educacional está fazendo água e um incomensurável naufrágio está bem diante dos nossos olhos. Precisamos agir rapidamente, para evitar que os milhões de crianças, jovens e pessoas com mais idade confrontados com o desafio da educação permanente, de reciclagem e de atualização contínuas não sejam engolidos pelo oceano da pseudo-ensino, de pseudo-aprendizagem, desta "soft education" em que "ninguém ensina coisa nenhuma a ninguém". Ao mesmo tempo, precisamos ampliar extraordinariamente as oportunidades de acesso ao ensino em todos os seus níveis e modalidades e estender sobremaneira a média de escolarização de nossa população, que é lamentavelmente muito baixa, em confronto com as de outros países em igual estágio de desenvolvimento ou mais avançado do que o Brasil.

Venho batalhando em favor do ensino à distância e das modernas tecnologias educacionais há cerca de quatro dezenas de anos. Batalhando como professor, pesquisador, divulgador e usuário e trabalhando diretamente na produção de filmes, vídeos e programas de rádio, na expansão do uso do computador e recursos a este associados em prol do ensino-aprendizagem. Ao longo dessa trajetória pessoal que começou com o cinema, o rádio e os impressos quando era um simples professor normalista e jornalista na metade do século, perguntei-me muitas e muitas vezes por que, apesar deste ou daquele esforço isolado e competente, destas ou daquelas iniciativas nos âmbitos governamentais ou privados, deste ou daquele projeto bem-sucedido em diferentes pontos destes brasis, por que entre nós não se desenvolveram plenamente, e portanto não puderam produzir frutos abundantes, semelhantes aos produzidos em outros países, as nossas tecnologias educacionais verde-amarelas, o nosso ensino à distância via rádio, cinema ou televisão. Isso, em parte, creio eu, aconteceu por falta de vontade política; por timidez, por má-vontade, da maioria dos nossos governantes e donos da educação no país; por resistências e temores infundados, como o de que os professores de sala de aula perderiam seus empregos; por mesquinharias, por provincianismos bocós que se recusam até hoje a admitir que um curso de química pelas mídias impressa, eletrônica ou por CD-Rom possa ser de excelente qualidade e produzir excelentes resultados em termos de ensino-aprendizagem independentemente da cidade, da região ou do país em que foi concebido e produzido. Há, no entanto, um "mea culpa" que cabe a nós, educadores e psicólogos em geral; às nossas instituições de ensino superior; aos nossos cursos de preparação do professorado que em tão má hora substituíram as antigas escolas normais, esfacelando tudo, abastardando tudo, enchendo as cabeças dos futuros docentes de pedagogismos e psicologismos pedantes, intolerantes e sem 
nenhum fundamento empírico, sem nenhum fundamento em pesquisa séria. Isto gerou o triste quadro de quase indigência psico-pedagógica que aí está.

É tempo de fazer, sob a bandeira de psicologia a serviço das escolas e dos escolares, com que se retome entre nós a lição dos anos 30, quando um pugilo de educadores e psicólogos, sob a liderança de Lourenço Filho, Anísio Teixeira, Fernando de Azevedo, Noemi Rudolfer, Leoni Kaseff, Venâncio Filho, Ulisses Pernambucano, Isaías Alves, Artur Ramos, Helena Antipoff e muitos outros sintonizou o ensino normalista e as práticas nas escolas com uma rica pluralidade de idéias e pesquisas, de procedimentos e concepções inovadoras, com um ecletismo saudável, fecundo e bastante pragmático. Leia-se os livros, os artigos e revistas daqueles tempos e ver-se-á que nenhum "ismo" arrogante, presunçoso, intolerante era imposto goela abaixo aos professores e futuros professores, ao contrário do que ocorre hoje em dia. Estimulava-se a flexibilidade, a versatilidade, a criatividade do professor, convidando-o a ler, discutir e usar na prática contribuições como as de Dewey, Montessori, Claparede, Thorndike, Decroly, Ferriere, Killpatrick, Watson, Pavlov, Aguayo, Kerchensteiner e tantos outros. Foi em meio a essa efervescência generosa, fecunda, estimulante, que Fernando de Azevedo dotou todas as escolas elementares da Capital Federal e da Capital Paulista de projetores e filmes cinematográficos educativos, que RoquettePinto e seus colaboradores lançaram as bases do rádio e do cinema educativos brasileiros, que Junqueira Schmit deu sua primeira contribuição pioneira para a tecnologia educacional a serviço do ensino de línguas estrangeiras, que Venâncio Filho publicou seu notável livro "A educação e seu aparelhamento moderno," nosso primeiro compêndio de tecnologia educacional, editado há cerca de 60 anos.

É preciso reacender essa antiga e generosa chama, em sintonia com as realidades novas, os novos recursos postos à disposição dos educadores neste limiar de um novo tempo, neste surpreendentemente "pior dos tempos e melhor dos tempos", como dizia Dickens no início do seu romance" Uma história de duas cidades" (1963).

Permitam-me aqui um breve parêntesis muito pessoal. Estamos na PUC-Campinas incentivando na pós-graduação em Psicologia Escolar as contribuições, sob a forma de disciplinas, teses e dissertações, e o empenho dos nossos estudantes pós-graduandos na área do ensino à distância, da mídia educativa, da tecnologia educacional. Várias teses e dissertações que temos orientado pessoalmente são o produto de pesquisas sérias, rigorosas, feitas recentemente neste domínio, como, por exemplo, as de Lima, Grinkraut, Barbosa e outros. É uma nova safra de pesquisadores sagazes, curiosos e competentes que estão construindo pontes sólidas de conhecimento entre a teorização, a investigação científica e a prática docente neste domínio. Tratase, no entanto, de um esforço até agora isolado, que gostaríamos de ver inserido num amplo quadro de pesquisas em todo o país, por psicólogos e pedagogos que se sintam atraídos pela temática aqui referida (v. Pfromm Netto, 1998).

Outro ponto de caráter pessoal que desejo ressaltar tem a ver com o recém-nascido e vigorosamente promissor CIANET de São Paulo. Mais do que promessa, o CIANET já é uma realidade. Nele estamos investindo com seriedade, com embasamento profissional, com generosidade e lucidez de propósitos, no ensino à distância e nas novas tecnologias educacionais. CIANET é um vastíssimo programa de ensino à distância, em forma de leque, que contempla desde a pré-escola até a pós-graduação e o desenvolvimento de recursos humanos em geral. Nasceu em janeiro último e busca a utilização do que de melhor dispomos em conhecimentos e habilidades alicerçados nas 
modernas pesquisas psicológicas e educacionais, para democratizar o ensino, torná-lo mais eficiente, gerar excelência educacional sob todos os aspectos. O CIANET é uma entidade aberta e privada. Não depende de recursos públicos, nem limita seu foco, suas estratégias e suas linhas de ação a uma única direção, pois realiza ao mesmo tempo, projetos próprios, trabalhos em cooperação ou parceria, "joint ventures", trabalhos de consultoria e serviço, estudos e investigações científicas. Esse amplo leque nos dá uma adaptabilidade, uma desenvoltura, uma agilidade e uma multiplicidade que se alinham muito bem com estes novos tempos.

É com base nos 40 anos a que me referi antes, de vivências, de alegrias (e de sofrimentos) em ensino à distância, tecnologia educacional e mídia educativa, e nas plataformas de pós-graduação em Psicologia Escolar da PUC-Campinas e da minha atual coordenação geral do CIANET que, para finalizar, quero propor-lhes, a quem já se vê às voltas com tantos desafios e perplexidades, um punhado de itens para a sua consideração e ação, que, de modo muito sumário, tentarei sintetizar e, se necessário, justificar.

$1^{\circ}$. Acreditem na educação à distância, na tecnologia educacional, na mídia educativa - e incorporem esses novos componentes do trabalho docente e do psicólogo escolar nas suas preocupações, nas suas agendas e no âmbito das suas intervenções, conselhos, consultoria e outras atividades profissionais como psicólogos escolares e/ou educacionais.

$2^{\circ}$. Não se deixem levar pelo falso dilema ensino em sala de aula ou ensino presencial, por um lado, contra ensino à distância por outro, como se este e aquele fossem inimigos inconciliáveis. A lição mundial a este respeito é que ambos se harmonizam, se apóiam mutuamente, se integram, a serviço da excelência no ensino-aprendizagem. Presentemente, aproxima-se de novecentas o total de instituições de ensino superior somente nos EUA e no Canadá que estão oferecendo ensino à distância, tanto de graduação como pós-graduação. Entre essas instituições, figuram algumas das melhores universidades do mundo. $\mathrm{Na}$ próxima semana estarei na Syracuse University - a universidade que mantém a "Eric Clearinghouse in Educational Technology", o centro de excelência do governo americano em matéria de tecnologias educacionais, mídia educativa e ensino à distância. Pois a Syracuse University, presentemente, oferece cursos que misturam ou integram ensino à distância e ensino presencial, inclusive em nível de pós-graduação. Um dos integrantes do CIANET, que é professor em Syracuse, contou-me que os seus alunos de pós-graduação não só aprovam a modalidade do ensino à distância pós-graduado como a consideram pasmem-se! - melhor do que o ensino presencial!

$3^{\circ}$. Ajudem-nos a modificar o estado de coisas que predomina no país em relação ao ensino à distância e às tecnologias educacionais. Em muitíssimo boa hora, o Governo Federal acaba de divulgar o Decreto que disciplina o ensino à distância. Devem muito em breve surgir as portarias específicas que detalham normas segundo as quais trilharemos os caminhos da educação à distância no país. Nós no CIANET e na PUC-Campinas estamos muito atentos aos rumos da elaboração dessa legislação e participamos atualmente com sugestões e recomendações nas reuniões que, nesse sentido, vêm sendo promovidas pela Associação Brasileira de Tecnologia de Educação - ABT - hoje sob a presidência vibrante, lúcida, corajosa de Walter Esteves Garcia. Procurem acompanhar esses rumos e seus desdobramentos. Quanto maior a participação, menores os riscos de infelicitarmos a 
educação à distância, a tecnologia educacional e a mídia educativa desde o nascedouro.

$4^{\circ}$. Escancarada ou disfarçadamente, está em marcha um movimento infeliz que, em pleno limiar do século 21, pretende menoscabar e até, se possível, suprimir a televisão e o rádio educativos no país, esses dois veículos específicos por excelência de educação à distância. Para quem não conhece a história do que têm sido as lutas, os dissabores, as frustrações e as resistências opostas à expansão, à consolidação e ao fortalecimento da tevê e do rádio educativos (ou públicos, ou não-comerciais) no Brasil, talvez não seja fácil entender o que está por trás dessas manobras, passa-moleques e até mesmo resistências encarniçadas que macularam a história dessa mídia educativa entre nós. Oxalá nossos governantes federais, estaduais e municipais não sucumbam aos "cantos de sereia" de interesses comerciais que apostam no fim da televisão e do rádio educativos no Brasil. É preciso mantê-los, é preciso expandi-los, é necessário apoiá-los para que cumpram com dignidade e eficiência sua missão neste nosso país continental. Nossas emissoras educativas de rádio e TV estão agonizantes, à míngua de recursos dos poderes públicos, limitadas a equipamentos obsoletos, a quadros exíguos de profissionais e vitimadas pela indiferença de boa parte dos nossos governantes e governados. Esta é uma realidade amarga, que precisa urgentemente ser modificada. Precisamos de mais e melhor televisão e rádio educativos, públicos e nãocomerciais.

$5^{\circ}$. Por fim, contribuamos todos para elevar o nível, sob todos os aspectos, do ensino à distância no país, da mídia educativa, de tecnologia educacional. Na sua expressão mais simples, educação à distância significa todas as formas de educação em que o aprendiz normalmente se encontra em um local diferente daquele em que se acha a pessoa que ensina, de acordo com Moore (Distance education at post secondary level, 1992, p.1097). No Peterson's Distance learning programs 1998, propõe-se um conceito mais pormenorizado de "aprendizagem à distância". Esta é o "fornecimento de programas educacionais a estudantes fora do local em que são originados, por meio do emprego de tecnologias como a televisão por cabo ou satélite, "teipes" de vídeo ou de áudio, fax, modem de computador, conferência por meio de computador ou videoconferência e outros meios de fornecimento eletrônico de ensino" (p.vii). Na edição mais recente de Foundations of distance education, Desmond Keegan (1996) propõe uma síntese conceitual de educação à distância apoiada em vários elementos básicos: (1) separação entre quem ensina e quem aprende, (2) existência de uma organização educacional que ministra o ensino à distância, (3) uso de mídia tecnológica impressa, mecânica ou eletrônica, (4) interatividade ou comunicação nos dois sentidos, (5) separação entre cada aprendiz específico e o grupo de aprendizagem, (6) possibilidade de encontros ocasionais para fins didáticos ou de socialização e (7) participação em uma forma industrializada de educação (p. 44-47).

Hoje em dia, no mundo inteiro há ensino à distância em todos os níveis e modalidades de educação, inclusive cursos universitários de graduação e pós-graduação, cursos individuais, cursos oferecidos para fins de obtenção de certificados profissionais e outros. A educação à distância, além disso, vem sendo usada de modo crescente em numerosos países para fins de educação permanente ou como complemento do ensino ministrado em sala de aula. Um dos componentes essenciais das novas formas de educação à distância é a interatividade, graças a recursos tecnológicos como o 
telefone, o satélite e a Internet. A expansão do ensino à distância tem sido universalmente exponencial, nos últimos anos. Ensino à distância - mídia educativa - tecnologia educacional inclua esses vocábulos no seu vocabulário de psicólogo ou de pedagogo. Inclua-os na sua

experiência, nos seus estudos, nas suas conversas. Inclua-os na sua ação junto a escolas, professores, alunos, autoridades de ensino. Inclua-os na sua vida.

\section{Referências}

Dickens, C. (1963). Uma história de duas cidades [Morrer por ela]. Rio de Janeiro: Vecchi (ed. original, 1859).

Dieuzeide, H. (1994). Les nouvelles technologies. Paris: UNESCO/NA THAN.

Faure, R. (1972). Apprendre à être. Paris: UNESCO.

Keegan, D. (1996). Foundations of distance education. London: Routledge.

Moore, M. G. (1992). Distance education at post secondary level. In: BR Clark \& G Neave, ed. The encyclopedia of higher education. Oxford: Pergamon,1097-1106.

Peterson 's Distance learning programs 1998. Princeton: Autor.

Pfromm Netto, S. (1998). Telas que ensinam. Campinas: Alínea. 